\title{
New mesogenic homologous series of $\alpha$-methylcinnamates
}

\author{
R A VORA and A K PRAJAPATI* \\ Department of Applied Chemistry, Faculty of Technology and Engineering, \\ MS University of Baroda, P. B. No. 51, Kalabhavan, Vadodara 390 001, \\ India \\ e-mail: akprajapati@yahoo.co.uk
}

MS received 27 September 2000; revised 26 December 2000

\begin{abstract}
Compounds of a new smectogenic homologous series of $\alpha$-methylcinnamates were prepared by condensing different 4- $n$-alkoxybenzoyl chloride with methoxyethyl trans-4-hydroxy- $\alpha$-methylcinnamate. In this series, the first six members are non-mesogenic. n-Heptyloxy derivative exhibits monotropic smectic A phase whereas rest of the members exhibit enantiotropic smectic A mesophase. The compounds are characterized by combination of elemental analysis and spectroscopic techniques. Enthalpies of few homologues are measured by DSC techniques. Fluorescent properties are also observed. The thermal stabilities of the present series are compared with those of other structurally related mesogenic homologous series.
\end{abstract}

Keywords. Smectic A; ambient temperature; $\alpha$-methylcinnamates.

\section{Introduction}

The advent of applications of liquid crystals in optical display devices led to an upsurge in the synthesis of room temperature nematic liquid crystals. Subsequently, it was established that smectic $\mathrm{A}$ as well as chiral smectic $\mathrm{C}$ phases have applications in advanced liquid crystal displays. This led to design of molecules which exhibit low melting smectic A and smectic $\mathrm{C}$ phases. Esters normally show smectic phases. Cinnamate esters have been well known for over 30 years and extensive literature exists $^{1-13}$. Vora and Rajput ${ }^{14}$ have reported binary mixtures of cinnamate esters exhibiting wide ranges of smectic and nematic mesophases. Recently, Sadashiva et al ${ }^{15}$ reported two mesogenic homologous series of cinnamate esters exhibiting ferroelectric and antiferroelectric phases. Aromatic esters with a broken alkoxy chain in the ester linkage have been less studied. In our previous study ${ }^{16}$, we reported that compounds containing a methoxyethyl and ethoxyethyl ester linkage exhibited SmA phase at ambient temperatures. In order to learn more about the effect of such ester linkage on mesomorphism, methoxyethyl trans-4(4'-n-alkoxybenzoyloxy)-a-methylcinnamates of the following structural formula (1) were synthesized and their mesogenic properties investigated.

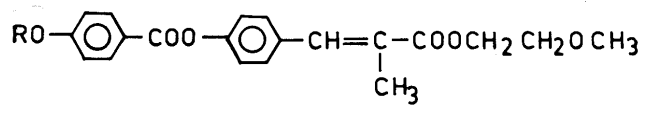

*For correspodence 


\section{Experimental}

\subsection{Characterization}

The chemical structures of intermediates and final compounds were confirmed by using a combination of elemental analysis (Coleman carbon-hydrogen analyser), infrared spectroscopy (Shimadzu IR-408) and ${ }^{1} \mathrm{H}$ NMR spectroscopy (Perkin-Elmer R-32). Liquid crystalline properties were investigated on a Leitz Laborlux 12 POL microscope provided with a heating stage. DSC was investigated on a Mettler TA-4000 system and fluorescent spectra was recorded on a Shimadzu Rf 540 spectrophotofluorometer.

\subsection{Synthesis}

4-Hydroxybenzaldehyde (BDH), propionic anhydride, sodium propionate, ethoxy ethanol, thionyl chloride (Sisco Chem), 4-hydroxybenzoic acid, $n$-alkyl halide (BDH) were used as received. All solvents were dried and distilled prior to use. The compounds of the new series (1) were prepared following the pathway shown in scheme 1.

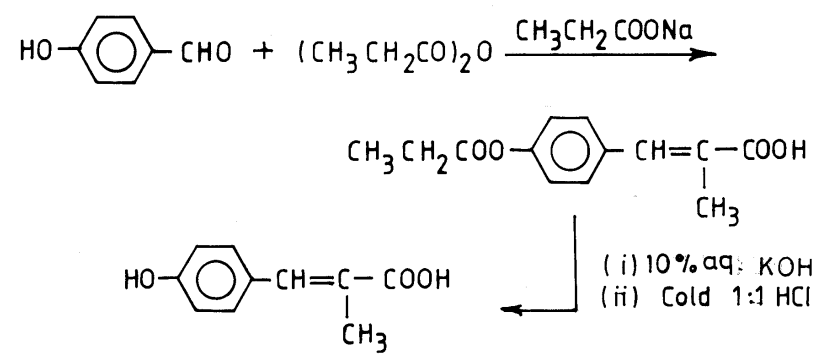

[A]

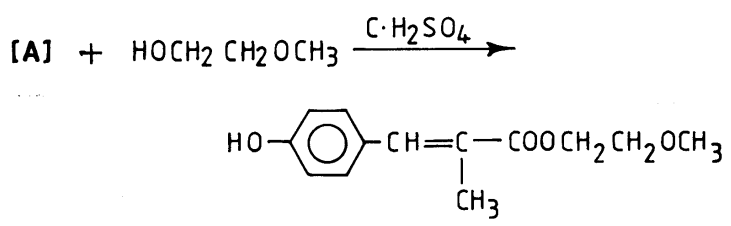

[B]
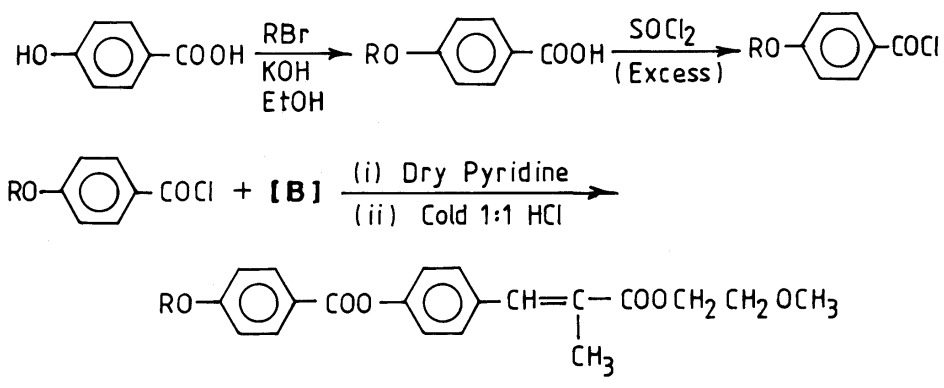

$$
\mathrm{R}=-\mathrm{C}_{\mathrm{n}} \mathrm{H}_{2 \mathrm{n}+1}, \mathrm{n}=4 \text { to } 8,10,12,14,16
$$

Scheme 1. Synthetic route to series 1. 
2.2a trans-4-Hydroxy- $\alpha-m e t h y l c i n n a m i c$ acid $(A)$ : This compound was synthesized by the method reported by Perkin ${ }^{17}$.

2.2b Methoxyethyl trans-4-hydroxy- $\alpha$-methylcinnamate $(B)$ : This compound was prepared by the conventional method of esterification of trans-4-hydroxy- $\alpha$-methyl cinnamic acid (A) with methoxyethanol using concentrated $\mathrm{H}_{2} \mathrm{SO}_{4}{ }^{18}$. The ester was crystallized several times from aqueous methanol. Elemental analysis: Found, C 66.40, $\mathrm{H}$ $6 \cdot 45 \%, \mathrm{C}_{13} \mathrm{H}_{16} \mathrm{O}_{4}$ requires $\mathrm{C} 66 \cdot 10, \mathrm{H} 6 \cdot 78 \%$. The IR ( $\mathrm{KBr}$ ) spectrum of the compound showed a broad peak of intermolecularly hydrogen bonded phenolic-OH between 3500 and $3100 \mathrm{~cm}^{-1}$. The COO-stretching vibrations were seen at $1705 \mathrm{~cm}^{-1}$. Other signals observed were at $1620\left(-\mathrm{CH}=\mathrm{C}\left(\mathrm{CH}_{3}\right)-\right), 1600,1520,1450,1385,1320,1285,1260$, $1190,1100,1035,990,850,760 \mathrm{~cm}^{-1}$.

2.2c 4-n-Alkoxybenzoic acids and 4-n-alkoxybenzoyl chlorides: These were synthesized by the modified method of Dave and Vora ${ }^{19}$.

2.2d General procedure for synthesis of compounds (1): Methoxyethyl trans-4hydroxy- $a$-methylcinnamates $(0.01 \mathrm{~mole})$ was dissolved in dry pyridine $(10 \mathrm{ml})$ and a cold solution of an appropriate 4- $n$-alkoxybenzoyl chloride $(0 \cdot 01$ mole $)$ in dry pyridine $(10 \mathrm{ml})$ was added slowly to it with constant stirring in an ice bath. The mixture was allowed to stand overnight at room temperature. It was acidified with cold 1:1 dilute hydrochloric acid. The product obtained was extracted with ether. The etheral extract was washed successively with water $(2 \times 30 \mathrm{ml})$, saturated solution of sodium bicarbonate $(2 \times 50 \mathrm{ml}), 10 \% \mathrm{NaOH}$ solution $(2 \times 50 \mathrm{ml})$ and water $(2 \times 30 \mathrm{ml})$. It was then dried $\left(\mathrm{Na}_{2} \mathrm{SO}_{4}\right)$. The residue obtained on removal of solvent was chromatographed on silica gel using petroleum ether $\left(60-80^{\circ} \mathrm{C}\right)$-ethylacetate mixture $(95: 5)$ as eluent. Removal of solvent from the eluate afforded a solid material which was crystallized repeatedly from methanol. The purities of all these compounds were checked by thin layer chromatography (Merk Kiesel gel 60 F254 pre-coated plates). Melting points and transition temperatures are recorded in table 1. The elemental analyses of all the compounds were found to be satisfactory (table 2). IR $\left(\mathrm{KBr}, \mathrm{cm}^{-1}\right)$ spectra: 2900,1725 (-COO-), 1635 (-HC=C(CH$\left.)_{3}-\right), 1600,1450,1270,1215,1160,1020,840,745$.

Table 1. Transition temperatures $\left({ }^{\circ} \mathrm{C}\right)$ for compounds $(\mathbf{1})$.

\begin{tabular}{lcccc}
\hline & \multicolumn{2}{c}{$\mathrm{R}=-\mathrm{C}_{n} \mathrm{H}_{2 n+1}$} & & \multicolumn{2}{c}{ Transition temperatures $\left({ }^{\circ} \mathrm{C}\right)$} \\
\cline { 2 - 2 } \cline { 5 - 5 } Compound no. & $n$ & & SmA & $\mathbf{1}$ \\
\hline 1 & 4 & & - & $73 \cdot 0$ \\
2 & 5 & & - & $41 \cdot 0$ \\
3 & 6 & & - & $38 \cdot 0$ \\
4 & 7 & & $38 \cdot 0)^{\mathrm{a}}$ & $38 \cdot 0$ \\
5 & 8 & & $33 \cdot 0$ & $43 \cdot 0$ \\
6 & 10 & & $40 \cdot 0$ & $54 \cdot 0$ \\
7 & 12 & & $51 \cdot 0$ & $61 \cdot 0$ \\
8 & 14 & & $59 \cdot 0$ & $64 \cdot 0$ \\
9 & 16 & & $66 \cdot 0$ \\
\hline
\end{tabular}

${ }^{a}$ Values in parentheses indicate monotropy 
Table 2. Elemental analysis of data for compounds $\mathbf{1}$.

\begin{tabular}{|c|c|c|c|c|c|}
\hline \multirow{2}{*}{$\begin{array}{l}\text { Compound no. } \\
\text { (table 1) }\end{array}$} & \multirow[b]{2}{*}{ Molecular formula } & \multicolumn{2}{|c|}{ Required (\%) } & \multicolumn{2}{|c|}{ Found (\%) } \\
\hline & & $\mathrm{C}$ & $\mathrm{H}$ & $\mathrm{C}$ & $\mathrm{H}$ \\
\hline 1 & $\mathrm{C}_{24} \mathrm{H}_{28} \mathrm{O}_{6}$ & $69 \cdot 90$ & $6 \cdot 80$ & $69 \cdot 63$ & $7 \cdot 08$ \\
\hline 2 & $\mathrm{C}_{25} \mathrm{H}_{30} \mathrm{O}_{6}$ & $70 \cdot 42$ & $7 \cdot 04$ & $70 \cdot 05$ & $7 \cdot 14$ \\
\hline 3 & $\mathrm{C}_{26} \mathrm{H}_{32} \mathrm{O}_{6}$ & $70 \cdot 91$ & $7 \cdot 27$ & $70 \cdot 48$ & $7 \cdot 08$ \\
\hline 4 & $\mathrm{C}_{27} \mathrm{H}_{34} \mathrm{O}_{6}$ & $71 \cdot 37$ & $7 \cdot 49$ & $71 \cdot 14$ & $7 \cdot 43$ \\
\hline 5 & $\mathrm{C}_{28} \mathrm{H}_{36} \mathrm{O}_{6}$ & $71 \cdot 79$ & $7 \cdot 69$ & $71 \cdot 37$ & $7 \cdot 26$ \\
\hline 6 & $\mathrm{C}_{30} \mathrm{H}_{40} \mathrm{O}_{6}$ & $72 \cdot 58$ & $8 \cdot 07$ & $73 \cdot 00$ & $8 \cdot 31$ \\
\hline 7 & $\mathrm{C}_{32} \mathrm{H}_{44} \mathrm{O}_{6}$ & $73 \cdot 28$ & $8 \cdot 40$ & $73 \cdot 41$ & $7 \cdot 96$ \\
\hline 8 & $\mathrm{C}_{43} \mathrm{H}_{48} \mathrm{O}_{6}$ & $73 \cdot 91$ & $8 \cdot 69$ & $73 \cdot 48$ & $8 \cdot 85$ \\
\hline 9 & $\mathrm{C}_{36} \mathrm{H}_{52} \mathrm{O}_{6}$ & $74 \cdot 48$ & $8 \cdot 96$ & $74 \cdot 96$ & $8 \cdot 56$ \\
\hline
\end{tabular}

Table 3. DSC data.

\begin{tabular}{lccrc}
\hline $\begin{array}{l}\text { Compound no. } \\
(\text { table 1) }\end{array}$ & $\begin{array}{c}\text { Heating time } \\
\left({ }^{\circ} \mathrm{C} / \mathrm{min}\right)\end{array}$ & Transition & $\begin{array}{c}\Delta H \\
(\mathrm{~J} / \mathrm{g})\end{array}$ & $\begin{array}{c}\Delta S \\
(\mathrm{~J} / \mathrm{gK})\end{array}$ \\
\hline 8 & 10 & Cr-SmA & 39.37 & $0 \cdot 1215$ \\
& \multirow{2}{*}{10} & SmA-1 & 1.93 & $0 \cdot 0057$ \\
& & Cr-SmA & 34.82 & $0 \cdot 1048$ \\
& & SmR-1 & 1.66 & $0 \cdot 0049$ \\
\hline
\end{tabular}

${ }^{1} \mathrm{H}$ NMR (n-dodecyloxy derivative, $90 \mathrm{MHz}, \mathrm{CDCl}_{3}$, standard TMS) $\delta 0.9(t, 3 \mathrm{H}$, $\left.-\mathrm{C}-\mathrm{CH}_{3}\right), 1 \cdot 1-1 \cdot 7\left(\right.$ brs $, 23 \mathrm{H}, 10 \times-\mathrm{CH}_{2}-$ and $\left.-\mathrm{C}=\mathrm{C}-\left(\mathrm{CH}_{3}\right)\right), 3 \cdot 35\left(\mathrm{~s}, 3 \mathrm{H},-\mathrm{OCH}_{3}\right), 3 \cdot 65$ $\left(t, 2 \mathrm{H},-\mathrm{COO}-\mathrm{C}-\mathrm{CH}_{2}-\right), 4.0\left(t, 2 \mathrm{H},-\mathrm{PhOCH}_{2}-\right), 4.3\left(t, 2 \mathrm{H},-\mathrm{COO}-\mathrm{CH}_{2}\right), 6.85$ $\left(d, J=9 \mathrm{~Hz}, 2 \mathrm{H}\right.$ at $\mathrm{C}-3^{\prime}$ and $\left.\mathrm{C}-5^{\prime}\right), 7 \cdot 15(d, J=9 \mathrm{~Hz}, 2 \mathrm{H}$ at C-3 and C-5), 7.35 $(d, J=9 \mathrm{~Hz}, 2 \mathrm{H}$ at $\mathrm{C}-2$ and $\mathrm{C}-6), 7 \cdot 6(s, 1 \mathrm{H}$ at $-\mathrm{Ph}-\mathrm{CH}=\mathrm{C}-), 8 \cdot 0(d, J=9 \mathrm{~Hz}, 2 \mathrm{H}$ at C-2 and $\left.\mathrm{C}^{\prime} 6^{\prime}\right)$, Enthalpies of $n$-tetradecyloxy and $n$-hexadecyloxy derivatives were measured by differential scanning calorimetry. Data are recorded in table 3.

\section{Results and discussion}

Lower members are non-mesogenic; the $n$-heptyloxy derivative exhibits monotropic smectic phase whereas rest of the members exhibit enantiotropic smectic phase. All the smectogens exhibit focal conic texture in polarizing microscope indicating that the smectic mesophase is of the SmA type. The type of smectic phase was further confirmed by miscibility study using 4-nitro-4'- $n$-decyloxy benzoate as standard material. An equimolar mixture of standard material and $n$-tetradecyloxy derivative of $\mathbf{1}$ was made by mixing them thoroughly in their isotropic states. (Transition temperatures $\left({ }^{\circ} \mathrm{C}\right)$ of mixture: $\mathrm{Cr} 43.0 \mathrm{~S}_{\mathrm{A}} 70.0 \mathrm{1}$ ). It is clear from this miscibility study that the smectic mesophase of $n$-tetradecyloxy derivative exhibited continuous miscibility with the smectic A mesophase of standard material. This indicated that smectogens of series (1) exhibited smectic A phase.

The plot of transition temperatures versus the number of carbon atoms in the alkoxy chain (figure 1) exhibits rising tendency of smectic-isotropic transition temperatures. 
Gray ${ }^{20}$ has explained the rising tendency of transition temperatures in low melting homologous series. Addition of each methylene group increases the polarizability and the length of the molecules which rises the mesomorphic-isotropic transitions. Gray ${ }^{20}$ has also explained the effect of lateral methyl group on mesomorphism. A lateral methyl group generally lowers the transition temperatures. Reference to figure 1 indicates that a sharp decrease in solid to mesomorphic transitions in the middle members is reponsible for the enantiotropic transition in the present series. However, in higher homologues, solid to mesomorphic transition temperatures exhibiting rising tendency.

Table 4 summarizes the average thermal stabilities and comparative geometry of the present series (1) and the structurally related series A[16], B[16] and C[10]. The average smectic thermal stability of series I is lower than that of series A and series B. Molecules of series $\mathbf{1}$ differ from series $\mathrm{A}$ and $\mathrm{B}$ only in the terminal linkage at one end. Molecles of series 1 have an additional $-\mathrm{C}=\mathrm{C}\left(\mathrm{CH}_{3}\right)$ - linkage at the terminus which makes the molecule a little longer and more polarizable as compared to molecules of series $\mathrm{A}$ and $\mathrm{B}$. However, the trans a-methyl group of series $\mathbf{1}$ contributes towards the increase in the breadth of the molecules. It has been observed that increase in the breadth of the molecules adversely affects the smectic phase compared to the nematic phase. It seems that the thickening effect ${ }^{20}$ caused by the $a$-methyl group has out balanced the effect of increased length and polarizability of molecules of series $\mathbf{1}$ by reducing its average smectic thermal stabilities.

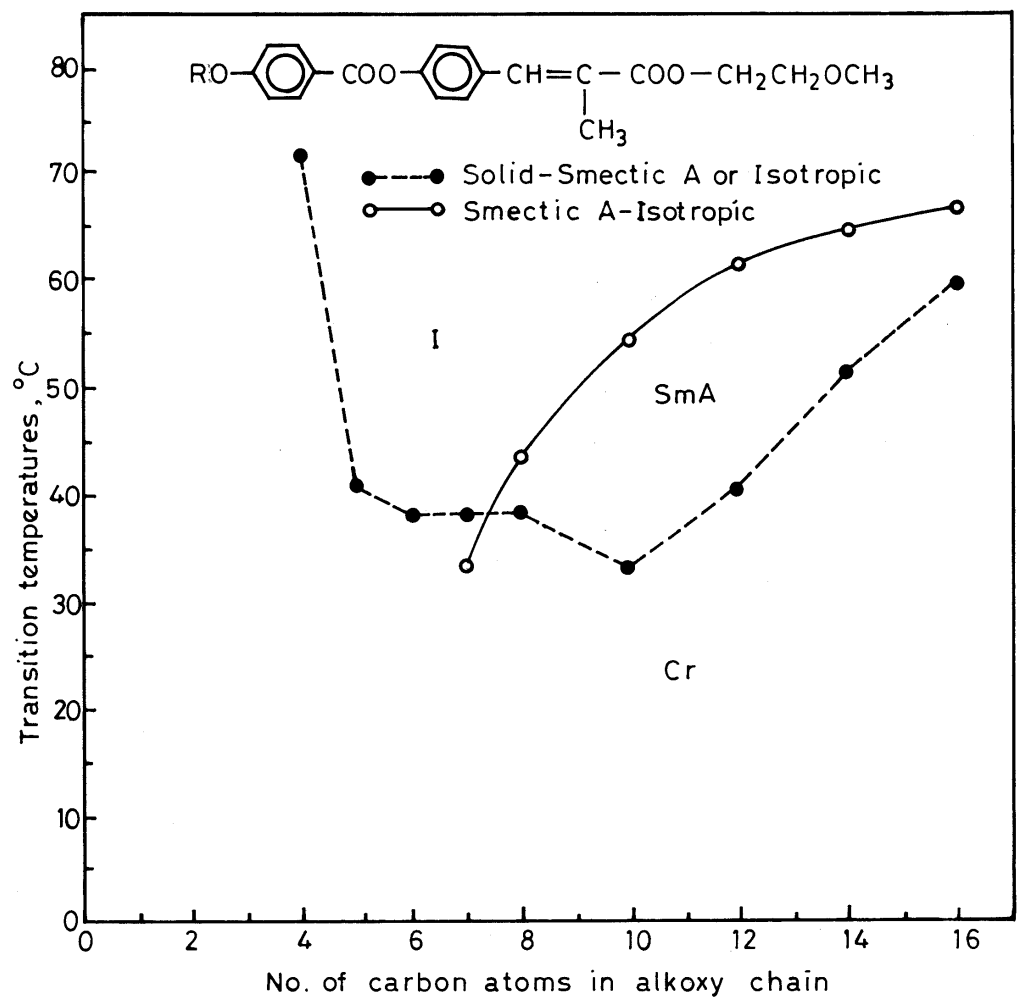

Figure 1. Phase behaviour of series 1 . 
Reference to table 4 indicates that the average smectic thermal stability of series $\mathbf{1}$ is lower than that of series C. Molecules of series $\mathrm{C}$ have $n$-butyl ester linkage at one terminus against the broken alkoxy terminus in the molecules of series $\mathbf{1}$. Moreover,

Table 4. Average thermal stabilities $\left({ }^{\circ} \mathrm{C}\right)$.

$$
\begin{array}{ll}
\mathrm{RO}-\mathrm{O}-\mathrm{COO} O \mathrm{O}=\mathrm{C}-\mathrm{COOCH}_{2} \mathrm{CH}_{2} \mathrm{OCH}_{3} & \text { Series } 1 \\
\mathrm{RO}-\mathrm{COO}-\mathrm{COO} O \mathrm{COO} \mathrm{CH}_{2} \mathrm{CH}_{2} \mathrm{OCH}_{2} \mathrm{CH}_{3} & \text { Series A } \\
\mathrm{RO}-\mathrm{COO}-\mathrm{CH}=\mathrm{CH}-\mathrm{COO}-\mathrm{O}-\mathrm{COOCH}_{2} \mathrm{CH}_{2} \mathrm{CH}_{2} \mathrm{CH}_{3} & \text { Series C }
\end{array}
$$

Comparative geometry of series $\mathbf{1}, \mathbf{A}, \mathbf{B}$ and $\mathbf{C}$.

\begin{tabular}{lcccc}
\hline Series & 1 & A & B & C \\
\hline Smectic to isotropic $\left(\mathrm{C}_{7}-\mathrm{C}_{16}\right)-$ & $53 \cdot 5$ & 56.33 & 66.33 & $106 \cdot 17$ \\
commencement of smectic phase & $\mathrm{C}_{7}$ & $\mathrm{C}_{5}$ & $\mathrm{C}_{5}$ & $\mathrm{C}_{2}$ \\
\hline
\end{tabular}
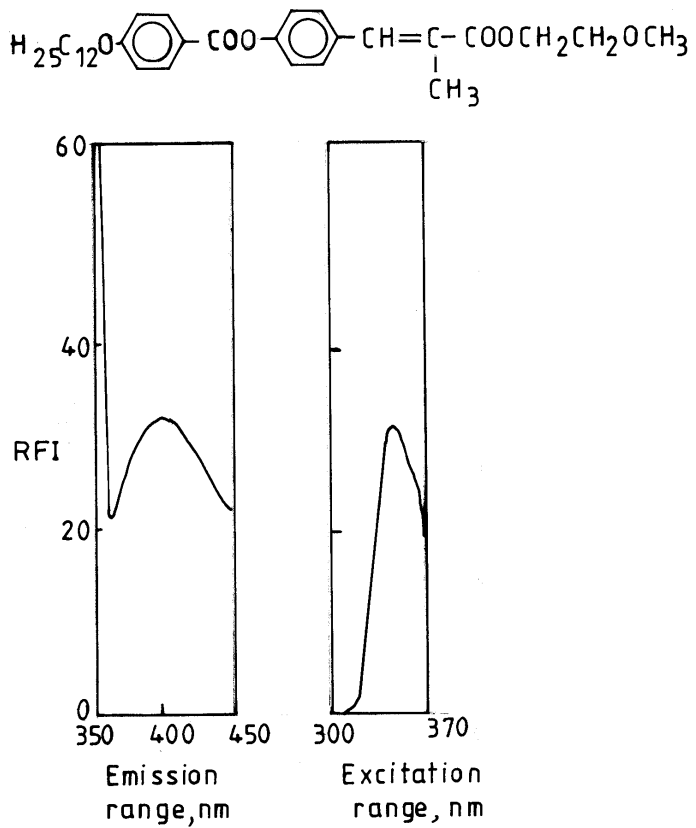

Figure 2. Fluorescence spectra of compounds (1). 
molecules of series $\mathrm{C}$ have a cinnamoyl group as a central linkage, which has no lateral $a$-methyl group, whereas molecules of series $\mathbf{1}$ have lateral $a$-methyl group on the cinnamoyl linkage at the terminus. All these factors enhance the smectic thermal stability of series $\mathrm{C}$ compared to series $\mathbf{1}$, which is the case.

\subsection{Fluorescent study}

The benzene ring with its six $\pi$-electrons can act in conjunction with electron-donating groups (auxochromes like $-\mathrm{NH}_{2}, \mathrm{RHN}-, \mathrm{R}_{1} \mathrm{R}_{2} \mathrm{~N}-,-\mathrm{O}-,-\mathrm{OH},-\mathrm{OR}$ etc.) and electronaccepting groups (like $-\mathrm{CN},-\mathrm{C}=\mathrm{C}-,-\mathrm{CO}-$ etc.) to produce strong absorption in the $\mathrm{UV}$ or visible regions which may give rise to fluorescence. Earlier Chudgar et al reported esters $^{21}$ and benzopyran-4[H] one heterocyclic ${ }^{22}$ mesogenic derivatives exhibiting fluorescent properties. With this in view, $n$-dodecyloxy derivatives of series $\mathbf{1}$ were studied for their fluorescent properties. Excitation and emission spectra were recorded for the compound on a Shimadzu Rf 540 spectrophotoflurometer at room temperature. The excitation spectra are records of luminescence intensity at fixed emissions as functions of the excitation wavelength. Fluorescence emission spectra are those in which excitation wavelength is kept constant and the corresponding wavelength distribution of the emitted radiation is measured. The excitation peak at $345 \mathrm{~nm}$ and the emission peak at $402 \mathrm{~nm}$ were observed (figure 2). This indicates that all the homologues of series $\mathbf{1}$ exhibit fluorescence property.

\section{Conclusion}

New mesogenic homologous series of $\alpha$-methylcinnamates were synthesized. The study indicated that the $\alpha$-methyl group on the cinnamoyl linkage adversely affects mesophase thermal stabilities. However the study has provided liquid crystalline compounds exhibiting smectic A phase at ambient temperature.

\section{Acknowledgments}

The authors thank Prof S G Shah and Prof U V Chudasama for encouragement.

\section{References}

1. Gray G W 1969 Mol. Cryst. Liq. Cryst. 7 127; Gray G W 1976 Advances in liquid crystals (ed.) G H Brown (New York, San Francisco, London: Academic Press) vol. 2, p. 1

2. Castellano J A, Goldmacher J E, Barton L A and Kane J S 1968 J. Org. Chem. 333501

3. Gray G W and Harrison K J 1971 Mol. Cryst. Liq. Cryst. 1337

4. Dave J S and Vora R A 1974 Mol. Cryst. Liq. Cryst. 28269

5. Kuschel F and Demus D 1975 Z. Chem. 15350

6. Titov V V, Kovsher E I and Pavluchenko A I 1975 J. Phys. (Paris) 36 C1-387

7. Dave J S and Lohar J M 1981 Mol. Cryst. Liq. Cryst. 70279

8. Lohar J M and Patel G H 1981 in Liquid crystals (ed.) S Chandrasekhar (Heyden Verlag), p 579; Lohar J M and Patel G H 1981 Mol. Cryst. Liq. Cryst. 7419

9. Subramanya R, Urs M and Sadashiva B K 1982 Mol. Cyst. Liq. Cryst. 72227

10. Agrawal Y K and Rajput S J 1990 J. Indian Chem. Soc. 67 369; Agrawal Y K and Rajput S J 1997 Indian Chem. Soc. 74689

11. Jones J F and Ratto J 1973 Chem. Commun. 21 841; Jones J F and Ratto J 1973 J. Chem. Soc. 847 
12. Titov V V, Kovshev E I, Pavluchenko A I, Lazareva V T and Grebenkin M F 1975 J. Phys (Paris) $36 \mathrm{C} 1-387$

13. Sadashiva B K 1976 Mol. Cryst. Liq. Cryst. 35205

14. Vora R A and Rajput S J 1991 Mol. Cryst. Liq. Cryst. 209265

15. Sadashiva B K, Kasthuraiah N, Krishnaprasad S and Nair G G 1998 Liq. Cryst. 24639

16. Vora R A and Prajapati A K 1994 J. Mysore Univ. B A33 61

17. Perkin W H 1877 J. Chem. Soc. 338

18. Vogel A I 1989 In Text book of practical organic chemistry 5th edn (London: ELBS and Longman) p. 1077

19. Dave J S and Vora R A 1970 In Liquid crystals and ordered fluids (eds) J F Johnson and R S Porter (New York: Plenum) p. 477

20. Gray G W 1962 In Molecular structure and properties of liquid crystals (London: Academic press)

21. Chudgar N K, Rathnam S, Shah A N and Sharma H C 1994 Mol. Mater. 4283

22. Chudgar N K, Parekh M K, Madhavrao S S and Sharma H C 1995 Liq. Cryst. 19807 